\title{
Ser, historia y escritura: Jacques Derrida y la «historicidad» en Martin Heidegger
}

\section{Being, history and writing: Jacques Derrida and «historicity» in Martin Heidegger}

\author{
MARCO ANTONIO NÚÑEZ CANTOS \\ Universidad Nacional de Educación a Distancia
}

Recibido: 04/10/2020 Aceptado:25/01/2021

\begin{abstract}
RESUMEN
El presente trabajo analiza la lectura que Jacques Derrida realiza de la noción heideggeriana de «historicidad» (Geschichte) en oposición a una concepción historicista de la «historia empírica» (Historie). En primer lugar, pretendemos exponer la complejidad de una lectura que bascula entre la proximidad a los planteamientos heideggerianos y la toma de distancia de los mismos tomando como referencia el seminario Heidegger: La cuestión del ser y la historia. En segundo lugar, procuraremos analizar las consecuencias de desplazar el concepto de «historia» al ámbito de la escritura y la economía de la différance, para generar una nueva conceptualidad sentando las bases de una nueva filosofía de la historia a partir del pensamiento de la huella.

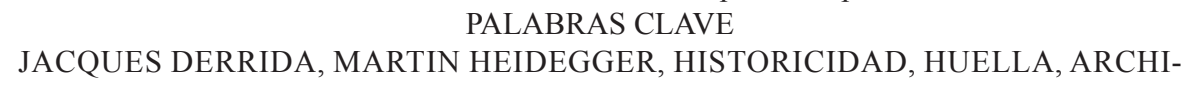

ABSTRACT

This paper analyzes Jacques Derrida's reading of the Heideggerian notion of «historicity» (Geschichte) as opposed to a historicist conception of «empirical history» (Historie). In the first place, we intend to expose the complexity of a reading that oscillates between the proximity to the Heideggerian approaches and the distancing of them, taking as reference the Heidegger seminar: The question of being and history. Secondly, we will try to analyze the consequences of moving the concept of «history» to the field of writing and the economy of différance, to 
generate a new conceptuality, laying the foundations of a new philosophy of history based on the thought of the trace.

KEYWORDS

JACQUES DERRIDA, MARTIN HEIDEGGER, HISTORICITY, TRACE, ARCHEHISTORY

\section{INTRODUCCIÓN}

MARTIN HeIDEGger SEÑALA QUE EL historicismo interpreta la historia como una secuencia de hechos empíricos (Historie) imbricados en una «temporalidad inauténtica», sucesiva y lineal que la reducen a mero dato, el objeto de estudio de la historiografía. La función de la Destuktion heidegegriana y su labor desedimentadora será la de conducirnos hacia el lugar ontológico de la historia y su enraizamiento originario a partir de una «temporalidad auténtica» consustancial al Dasein, la «historicidad» (Geschichte). En consecuencia, la Destruktion del concepto de «historia» solo será la destrucción de un cierto «concepto de historia».

Sin embargo, Jacques Derrida sospecha que el nuevo concepto ontológico de historia que Heidegger opone a la historia fáctica del historicismo, como lo trascendental se opone a lo empírico, tampoco está libre de determinaciones típicamente metafísicas. Veremos que Derrida se sirve de la la compleja noción de «metaforicidad» para suprimir la oposición entre Historie y Geschichte generando una nueva conceptualidad donde el concepto de «historia» pasa a funcionar como un «cuasi-trascendental» que permite pensar en la historia como un movimiento abierto de desplazamientos metafóricos, el lugar de todas las inscripciones históricas y el movimiento mismo a través del cual las marcas históricas se vuelven legibles. La historia deviene una forma de escritura que escapa a su formulación metafísica a partir del ese vínculo presupuesto siempre, pero siempre impensado: la inscripción empírica que se concentra en el registro del pasado para el futuro.

En la primera sección, el punto de partida de nuestra investigación será el documento que, como señala Sean Gaston en un reciente estudio, Jacques Derrida and the Challenge of History, sienta las bases para una filosofía de la historia y una deconstrucción de la historiografía (Gaston 2019, p. 1). Se trata del seminario que Jacques Derrida impartió en la École Normale Supérieure de París durante el curso 1964-1965 publicado en 2013 bajo el título Heidegger: la cuestión del Ser y de la Historia, donde lleva a cabo una lectura de los parágrafos $\S 72$ y $\$ 73$ de Ser y tiempo. Lo notable de este comentario seminal, dentro aún de un esquema fenomenológico que se interroga por la esencia 
de la historia, es que perfila temas de su propio interés en conjunción con el texto de Heidegger, delineando las dificultades y los límites de la empresa heideggeriana debida a los planteamientos propios de la analítica existencial del Dasein y cierta concepción de la temporalidad.

En la segunda sección nos aproximaremos a la filosofía de la historia derridiana desde el pensamiento de la huella y la condiciones de (im) posibilidad de una ontología de la no-presencia abierta a la venida de lo otro. En efecto, para Derrida el movimiento de la temporalización es inseparable e impensable fuera de la relación con una alteridad que siempre está en camino y nunca es presente. En De la gramatología se propone una historicidad emergente desde el juego de las huellas que ni son sensibles ni inteligibles, ni totalmente ausentes, ni plenamente presentes, así como desde el dinamismo de la différance que tampoco es meramente activa, ni pasiva. La operación de nociones clave en el pensamiento derridano como la trace,écriture o différance, sustraen al concepto de historia de sus contextos semánticos habituales y lo reinscriben en una nueva cadena conceptual que permite superar la dicotomía entre lo empírico y lo trascendental ${ }^{1}$ subyacente al par Historie/Geschichte, resultando una «archi-historia» $\mathrm{o}$ «historia radical».

\section{HISTORICIDAD Y SER}

\section{2.1. LA HISTORICIDAD COMO CONSTITUCIÓN DEL DASEIN}

En Ser y tiempo, Heidegger intentó establecer una nueva comprensión de la historia desvinculada del sujeto metafísico y libre de la primacía de la presencia, desde la que fuera posible una ciencia de la historia sobre la analítica existencial del Dasein. La operación de la analítica ontológicoexistencial del problema de la historia desde la comprensión del ser del Dasein, permite a Heidegger reducir lo empírico de la historia concreta a la estructura del ser de lo histórico y lo hace derivar de ella. Es decir, la historicidad (Geschichte) «designa un acontecer que somos nosotros mismos y en el cual estamos implicados» (Heidegger 2009, p. 92). Heidegger llama «acontecer» (Geschehen) a esta historicidad como constitución del ser del Dasein, un acontecer que, en cuanto pasado, todavía está ahí. En este sentido, para referir la condición existencial mínima del Dasein y su estar en el mundo, Heidegger utiliza la locución adverbial: «ya siempre» (immer schon), donde el «ya» indica un acaecimiento, algo ya pasado; mientras el «siempre» supone

1 Husserl, en menor medida, y, especialmente, Derrida, desmontan la dicotomía que opone lo a priori (universal y necesario) a lo a posteriori (contingente y empírico), «reconociendo que puede existir una necesidad en la experiencia, que se determina a posteriori» (Ferraris 1990, pp. 339-395). 
una temporalidad que puede superar la contingencia en una continuidad sin inicio y sin fin, y, por esto mismo, fuera de la historia. Pues bien, en el trayecto que se perfila entre el «ya» y el «siempre», tiene lugar la noción de temporalidad heideggeriana y que define con la figura del círculo, una circularidad que no se resuelve en ninguno de los opuestos y que no se puede sintetizar, manteniéndose al nivel de una contradicción. Siendo esto es lo más propio de la historicidad, la imposibilidad de un punto de partida puro en la proximidad de lo óntico y lo ontológico:

La circularidad es historicidad: esto es, la gravedad de un ya existente que pesa y le da su lugar, su centro, a la cuestión del ser que siempre ha comenzado a invocarnos [...] Este círculo y comienzo en lo pre-ontológico, que no es ni el no-sentido del ser ni el concepto explícito del significado del ser, explican esta unidad de lo cercano y lo lejano, de un $D a$ que es un aquí y un allá, y en primer lugar el movimiento que los reúne, y de que la lógica metafísica no puede pensar sino como contradicciones. Las contradicciones son la historicidad: es decir, la imposibilidad de un punto de partida puro en la proximidad absoluta de lo óntico o lo ontológico [...] y la necesidad, por lo tanto, de partir de lo pre-ontológico (Derrida 2016, p. 90)

Ahora bien, si, por un lado, Heidegger mantiene este círculo que no se cierra y persevera la inadecuación del «siempre» al «ya» y del «ya» al «siempre»; por otro lado, su argumento parece sugerir cierto deseo $^{2}$ de cerrar el círculo, cierta aspiración a un horizonte unitario del acontecer en la «historicidad auténtica» (Potestà 2017, p. 236). Sin embargo, a medida que el problema de la historicidad es reconducido a su raíz, la temporalidad, gradualmente se pierden las determinaciones categoriales y la seguridad de un horizonte unitario, como consecuencia de la labor destructora, los rasgos esenciales de la historicidad se disuelven progresivamente. Con todo, el anuncio del estudio de la temporalidad del ser en una tercera sección de Ser y tiempo nunca publicada, anticipa cierto deseo de superar la falta de horizontes y la duplicidad del «siempre ya».

\section{2.2. HISTORICIDAD Y TEMPORALIDAD}

Como se ha visto, Heidegger parte del análisis de la realidad efectiva del Dasein y su esencia temporal para interrogarse por la historicidad. Lo histórico es posible porque el Dasein es temporal en su ser, y la historicidad le es constitutiva por hallarse estrechamente vinculada a su esencia. El Heidegger tardío sostiene que, en sentido estricto, no puede haber otra historia que de la

2 Wood habla de que el tratamiento que Derrida dispensa a la filosofía puede ser entendido como una «hermeneútica del deseo» (Wood 1989, p. 268). 
«historia del ser», porque el ser solo llega en $s u$ historia que no es otra cosa que la historia de una retirada. Así las cosas, podría pensarse que el ser no es más que una grieta, una hendidura, la apertura de toda posible historia -a este respecto la opinión de Derrida será muy distinta, como tendremos ocasión de precisar-, y si el ser mismo es pensado como histórico, la historia ya no puede ser confundida con una secuencia de hechos empíricos, como ocurre en la historiografía. Dicho de otro modo, el fundamento del ser de lo histórico, la historicidad, es una «temporalidad originaria y propia» que subyace a su posible tematización por medio del saber histórico, su tratamiento como objeto efectivo de conocimiento, lo que Heidegger denomina «caracterización vulgar de lo histórico», y que se sostiene sobre una interpretación vulgar del carácter temporal de la historia. De modo que, la historicidad auténtica habría sido velada por la «concepción vulgar del tiempo» que suscribe la filosofía clásica desde Aristóteles, y debe ser elucidada sobre la base de una temporalidad auténtica, originaria y propia. A este respecto, Heidegger dedicará en la §82 de Ser y tiempo una larga nota a pie de página a comentar la noción de tiempo en Aristóteles, caracterizado en la Física como el pasar de los «ahoras». La interpretación de esta concepción del tiempo plantea una difícil disyuntiva ${ }^{3}$. En efecto, si, por un lado, admitimos que el tiempo se compone de «ahoras» y estos «ahoras» son determinados como un «no todavía», deberemos concluir que el tiempo, en cierto modo, «no es»; pero si, por otro lado, negamos que se componga de «ahoras», es decir, si aceptamos que tenga partes discretas, deberemos concluir que es eterno, indivisible: presencia absoluta y atemporal. Esta determinación ideal del tiempo se corresponde para Heidegger con el olvido del ser en la medida en que se niega el movimiento fenoménico del aparecer, de la desocultación del fenómeno, y el tiempo es pensado como una línea continua. Hegel seguirá esta concepción cuando reduzca las tres dimensiones temporales, presente, pasado y porvenir, a momentos que deben ser dialécticamente superados. En ambos casos asistimos a una espacialización del tiempo, así como a la concesión del privilegio de una dimensión temporal muy concreta, el «ahora-presente», es decir, en esta concepción aristotélicohegeliana el tiempo se piensa desde la prioridad de la presencia, pero nunca en su especificidad. Esta sería la caracterización de una «temporalidad inauténtica» responsable de la «historicidad inauténtica» tematizada por el historicismo.

A lo largo de la segunda sesión del Seminario, Derrida incide sobre este mismo argumento desde la perspectiva de una nueva conceptualidad que le permite mostrar el límite constitutivo del planteamiento heideggeriano,

3 En «Ousía y grammè» Derrida reprocha a Heidegger no haber reparado en la fuerza aporética de la proposición aristotélica que permite pensar el tiempo como diferenciación originaria. 
y para ello retoma la expresión con la que Husserl en las Ideas $I^{4}$ marcaba la exigencia de un retorno a lo primitivo: «No se cuentan aquí historias». Por «contar historias» Heidegger entiende construir una estructura de inteligibilidad metahistórica de dominación de los hechos fundamentada sobre una «temporalidad inauténtica», algo que equivale de nuevo a asimilar el ser al ente, ignorando la diferencia entre lo que se intenta contar y el cuento mismo, entre la vivencia y el saber de esta vivencia, con la consiguiente mistificación del hecho concreto al ser reducido a un puro dato. No quiere ello decir que cada explicación óntica degenere necesariamente en un «contar historias», porque cuando la ciencia determina causalidades o legalidades que ordena la relación entre los entes, no se está necesariamente contando historias, se «cuentan historias» únicamente cuando aquellas explicaciones exceden el ámbito de su discurso y pretenden dar respuesta a la cuestión del significado del ser.

$\mathrm{Si}$ en lo relativo a la «temporalidad inauténtica» la Destruktion heideggeriana señalaba, en primer lugar, a Aristóteles como responsable de las determinaciones categoriales de la tradición que aspira a destruir con su gesto, ahora su proyecto de suprimir esta estructura fija de conceptualización desde la que pensar la historia históricamente para mantener la proximidad con el acontecer concreto y fáctico, tiene como principal exponente a Hegel. En este sentido, Derrida establece un paralelismo entre la Destruktion de la historia de la ontología como labor desedimentadora, con la propuesta más radical de Hegel en que la historicidad solo puede dar comienzo con el «fin de la historia», es decir, con una refutación total y absoluta del pasado, insistiendo más adelante en la ausencia de cualquier experiencia de conciencia en Ser y tiempo como la diferencia decisiva entre ambos.

Llegados a este punto debemos señalar que, pese a los esfuerzos de Heidegger por establecer el fundamento ontológico de la historia, Derrida no puede menos que mostrar extrañeza (Derrida 2016, pp. 165-166) ante el siguiente hecho, y es que después de afirmar que la «historicidad auténtica» ha sido velada por una concepción «inauténtica de la historia», Heidegger prosigue definiendo «lo inauténtico» y «lo derivado», en vez de otorgar prioridad a «lo originario y auténtico». Y su justificación no parece de índole metodológica como cabría esperar, según Derrida probablemente responda

4 «No se cuentan aquí historias. Al hablar de primigenidad no se necesita ni se debe pensar en una génesis causal-psicológica, ni en una génesis histórico-evolutiva. A qué otro sentido se alude, sólo se aclarará en forma reflexiva y científica más tarde. Pero, desde luego, siente cualquiera que la anterioridad del conocimiento concreto-empírico de hechos a cualquier otro, por ejemplo a todo hecho ideal-matemático, no tendría que tener un sentido temporal-objetivo» (Husserl 2013, pp. 87-88). 
al hecho de que no se trata de un error que deba ser corregido, antes bien, conforma una cierta estructura existencial del Dasein consistente en pensar que el sujeto es en la historia reflejo de la estructura del ser en el tiempo que es la forma inauténtica de la ex-istencia temporal. De este modo, «el concepto vulgar de la historicidad» y la «historicidad inauténtica» se enraízan en la intratemporalidad (Innerzeitigkeit), y lo inauténtico resulta no ser una mera contingencia sino una necesidad estructural, de donde se colige que «lo auténtico primero que no es lo primero» (Derrida 2016, p. 165).

Ahora bien, como ya fue apuntado, para Heidegger no puede haber otra historia que la «historia del ser» que no es otra cosa que la historia de su retirada en lo óntico y su posterior olvido, con lo que el ser marcaría la apertura de toda posible historia. Sin embargo, Derrida niega que el ser sea la hendidura que abre la posibilidad de la historia, a su juicio, lo que hace la diferencia ontológica de hecho es cerrarla, estableciendo así la posibilidad de una diferencia más originaria e irreductible a una simple unidad inicial o final (Ibid, 208) en solidaridad con la idea de la imposibilidad toda determinación real de un comienzo, «la historia del ser» se ve sustituida por la proliferación de una multiplicidad irreductible de historicidades.

En suma, las dos objeciones que Derrida señala en relación a la noción heideggeriana de «historicidad» son las siguientes:

1. La cuestión de la «historicidad auténtica» no se aborda realmente en Ser y tiempo, Heidegger no llega a ofrecer en ningún momento un planteamiento de la cuestión sobre la historicidad como tal (Ibid, 164) en sentido propio, a diferencia de la historicidad del Dasein, que es extensamente desarrollada. Derrida establece un vínculo entre «lo propio» ${ }^{5}$ y la historicidad, y denomina a este gesto «ex-propiación», en cuanto pérdida temporal de propiedad en relación con una alteridad no presente, un otro ausente que no es «propio». Es en el enclave de esta heterogeneidad emergente en la historicidad donde Sean Gaston cifra el punto de partida del pensamiento de la historia derridiano (Gaston 2019, p. 67). En efecto, frente al planteamiento de Heidegger, donde la historicidad del Dasein precede a «la historia del ser», Derrida considera que el sentido propio de la «historicidad auténtica» se encuentra suspendido por obra de la différance (Derrida 2016, pp. 163-164). Y una de las implicaciones de pensar la historia desde una perspectiva más radical, como es la noción de différance, consiste en eliminar la suposición de proximidad como origen.

5 «Lo originario, lo auténtico está determinado como lo propio (eigentlich), es decir, lo próximo (propio proprius), el presente en la proximidad de la presencia para sí. Podríamos mostrar cómo este valor de proximidad y de la presencia para sí intervienen, en el principio de Ser y tiempo y en otras partes, en la decisión de plantear la cuestión del sentido del ser a partir de una analítica existencial del Dasein» (Derrida 2013, pp. 98-99). 
Derrida explica que, en relación con el ser, el allí o $D a$ del Da-sein no está ni cerca ni lejos (Ibid, 87), porque se resiste a la espacialidad tanto como a cualquier otra designación de naturaleza antropológica, y vincula esta oscilación a una historicidad abierta por obra de la différance superadora de «la diferencia óntico-ontológica».

2. La segunda objeción esboza ya una deconstrucción del texto heideggeriano al apuntar hacia su axiomática constitutiva, una conceptualidad presupuesta e incuestionada que permite la distinción jerárquica entre el conocimiento óntico y el ontológico implícita ya en la anterior objeción respecto a «lo próximo», razón por la que para Derrida, el concepto de historia no se deja pensar a partir de los términos de la oposición entre Geschichte e Historie como acertadamente señala (Marrati 2005, p. 87 y ss; 106). En efecto, en más de una ocasión Derrida volvió sobre la distinción entre «historiografía» (Historie) y «acaecimiento histórico» (Geschehen) a fin de cuestionar la prioridad de la «historicidad» (Geschichte), dado que presupone la jerarquía «original/derivado» inseparable del par «auténtico/ inauténtico». Naturalmente, sendos pares se hallan vinculados a la diferencia ontológica que dicta la distinción entre ambos. Sin embargo, la différance precede y prolonga la diferencia ontológica en la medida en que ni «antes» ni «después» son absolutos, sino efectos producidos por un sistema de clausura que difiere de la diferencia y arruina las nociones parejas de «origen» (arjé) y «fin» (telos). Años más tarde en Dar (el) tiempo Derrida desarrolla la típica estrategia deconstructiva de inversión de la oposición Geschichte/Historie y procede a su reinscripción en una nueva cadena conceptual:

Señalémoslo de paso: en toda situación en donde la posibilidad del relato en la condición de la historia, del acontecimiento histórico, habría que poder decir que la condición o el deseo de saber (episteme, historia rerum, gestarum, Historie) da lugar a la historia misma (res gestae, Geschehen, Geschichte), lo cual podría complicar si no, finalmente contradecir muchas argumentaciones de tipo hegeliano o heideggeriano que siempre parecen requerir un orden inverso (no hay Historie sin Geschichte), pero es cierto esto se debe a que, previamente, se ha integrado la posibilidad del relato o de la relación de saber en la del acontecimiento (Derrida 1995, pp. 121-122).

Las características principales del replanteamiento que Derrida lleva a cabo de lo trascendental como «cuasi-trascendental», conduce a una reconfiguración de la historicidad como un infinito abierto, cuya indeterminación fruto de su finitud permite un replanteamiento de la Historie que ya no se opone a la Geschichte del modo en que lo empírico se opone a lo trascendental. Y el principal corolario de la reinscripción de estas nociones en una nueva articulación sintagmática donde la oposición no resulta operativa en términos 
absolutos, es la imposibilidad de parar de «contar historias», en la medida en que elaborar un discurso implica siempre jugar con la différance, instalarse en la metáfora, como habrá ocasión de ver en el siguiente apartado.

Derrida escribirá poco después: «La différance no pertenece simplemente ni a la historia ni a la estructura» (Derrida 2012, p. 44), precede esta oposición entre lo empírico y lo trascendental, y la abre sin que haya forma de resolver el círculo ni de cerrarlo pese a los deseos de Heidegger. En conclusión, no es posible escapar a la ficción, dejar de «contar historias» del mismo modo que no hay un afuera de la metafísica, por eso, en vez de salir o de encontrar una solución a la dominación mentirosa, se trata más bien de hacerse cargo del círculo interrumpido y de la imposibilidad de salir del «siempre ya».

\section{2.3. HISTORICIDAD Y METAFORICIDAD}

Si el concepto de historia implica preguntarse por la esencia que lo regula, también supone la pregunta por la historia misma de la esencia que en última instancia es una interrogación por la historia del sentido del ser, se hace necesaria de una estrategia de trabajo textual que cambie el concepto tradicional de historia para evitar que sea reapropiado metafísicamente (Derrida 2014, pp. 93-94), asumiendo el riesgo implícito en la conceptualización misma, de ahí que haya siempre que interrogar a los conceptos desde la especificidad de su historia y su articulación con los demás campos históricos del texto general. Con este propósito, Derrida traduce los motivos heideggerianos de «la diferencia ontológica», «el lenguaje» y de «la verdad del ser» en términos de un pensamiento de la metaforicidad (Derrida 2016, pp. 222-223), regulado por la economía de la différance, aunque este término aún no se explicite en el seminario. Si para Heidegger, como hemos visto, la esencia de la historia es la historicidad, al menos, la historicidad del Dasein, Derrida, por su parte, consciente de que al plantear la pregunta por la esencialidad que regula un concepto se corre el riesgo de apropiación metafísica, sigue el mismo procedimiento en relación a la metáfora, y afirma que la esencia de la metáfora es la metaforicidad «como tal», para acto seguido transformar esta correspondencia en un quiasmo saltando del ámbito de la metáfora al de la historia, para establecer una analogía sobre la base de la solidaridad eidética que une sus respectivas esencias, ese carácter de «como tal».

Antes de proseguir, debemos precisar que la noción de esencia que Derrida contempla es la de Heidegger no la de Husserl, es decir, en lugar de designar la ley eidética que permite metáfora e historia como posibilidades alcanzadas por la intuición de un sujeto trascendental, el «como tal» de la metáfora y la historia debe ser entendido como un movimiento de ocultamiento y desocultamiento. La disimulación es lo más esencial de la estructura de estos dos «como tal», y, en consecuencia, metaforicidad e historicidad establecen 
el cierre del campo de la historia. La historia «como tal» se anuncia solo a través del infinito de sus disimulaciones, configurándose como un entramado de acontecimientos de metáforas, esto es, de acontecimientos históricos que se refieren a otros sucesos históricos, que se refieren a otros sucesos históricos, y así sucesivamente en una suerte de puesta en abismo:

Si uno considera que la metáfora es interminable y que es la ocultación óntica de la verdad del ser por lo óntico, esta metaforicidad que es la esencia misma de la metafísica, entonces uno se da cuenta de que (1) no hay posible superación, Überwindung de la metafísica [...] Y esto es así (2) porque lo que es absolutamente fundamental no es ni el ser, que no es nada, ni los entes, sino la diferencia ontico-ontológica; porque la inautenticidad metafórica no puede ser superada y no figura, ya que no es autenticidad, como un accidente revocable y evitable (Derrida 2016, p. 63).

Si para Heidegger el pensamiento del ser anuncia el horizonte no metafórico de todas las metáforas es, precisamente, porque insiste en la irreductibilidad de la diferencia entre el ser y los entes, y pugna para transformar el pensamiento mismo en una pregunta que no aspira a superar esa diferencia, antes bien, incrementa la diferencia y su ocultación a lo largo de la historia de la filosofía. De este modo, la cuestión del ser «como tal» y de «la diferencia ontológica» pueden ser vistas como sedimentaciones históricas del disimulo estructural y necesario del ser. Al insistir en el hecho de que ningún ente, ningún nombre podría ser «el nombre del ser», la cuestión del ser se convierte en el movimiento mismo a través del que cada metáfora es metáfora en la medida en que la disimulación y el auto-ocultamiento son sus condiciones más propias. Aquí encontramos una de las primeras formulaciones de la différance, poco más tarde desarrollada en la célebre ponencia bajo el mismo título.

En suma, (1) la metaforicidad nombra a la historia «como tal» en la medida en que designa el infinito o la totalidad abierta de disimulación que constituye la esencia de la historia, y a su vez, (2) la historicidad nombra a la metáfora «como tal» porque esta última también debe permanecer estructuralmente abierta al infinito movimiento de transmisión ${ }^{6}$. De modo que metáfora e historia son lo mismo en cuanto que solo pueden disimularse

6 Recordemos que para el Heidegger de «El fragmento de Anaximandro» la historia del ser era una transferencia en el lenguaje, a pesar la historia de las malas lecturas, de la cuestión del ser en relación al despliegue uniforme del tiempo. Tal traducción ocurre por medio de estructuras metafóricas en cuya aparición la verdad es diferida, aunque, esta verdad como el proceso de traducción o metaforización mismo, está continuamente manifestándose a sí misma en el momento de su ausencia y retracción, dejando la marca de una marca, el retrait. Derrida abordará este asunto por extenso en «La retirada de la metáfora». 
desde el principio. Naturalmente, este principio no coincide con los valores tradicionalmente asociados con el concepto de «origen», como la presencia o la simplicidad.

Derrida piensa en esa historia del ser como una historia de las metáforas y suscribe la sugerencia de Jorge Luis Borges de que la historia universal «es quizás solo la historia de algunas metáforas o de varias inflexiones de algunas metáforas» (Derrida 2016, p. 190). En «La retirada de la metáfora» aplica esta idea a la historia de la metafísica que es contemplada como un proceso estructural donde la epojé del ser, al retenerse, es decir, al mantenerse el ser retirado, se presenta en una serie de metáforas: «La metafísica no habría construido y tratado sólo el concepto de metáfora, por ejemplo, a partir de una determinación del ser como eidos; ella misma estaría en situación trópica respecto al ser o al pensamiento del ser» (Derrida 1989, pp. 56-57). El seminario concluye con el motivo heideggeriano de la «destrucción de metáforas» como la tarea de pensamiento, y el papel crucial que a este respecto desempeña la diferencia ontológica por la posibilidad que ofrece de entender las metáforas como metáforas:

Si el ser y la historia son expresiones metafóricas en proceso de destruirse a sí mismas como tal, entonces podemos hablar de un fin de la historia y una muerte del ser, que son, no en menor medida, lo que por otra metáfora podemos llamar el futuro mismo. Lo que se encuentra oculto bajo esta otra metáfora es la apertura de la cuestión misma: esto es, de la diferencia (Derrida 2016, pp. 224-225).

\section{HISTORICIDAD Y HUELLA}

Dos años después de la lectura del seminario en la École, Derrida publica De la gramatología, la principal diferencia es que Derrida ahora argumenta que la historicidad misma y la relación entre Geschichte e Historie deben pensarse desde escritura en general, desde la différance:

$6^{\circ}$ que la historicidad misma está ligada a la posibilidad de la escritura: a la posibilidad de la escritura en general, más allá de las formas particulares de escritura, en nombre de las cuales durante mucho tiempo se ha hablado de pueblos sin escritura y sin historia. Antes de ser el objeto de una historia - de una ciencia histórica - la escritura abre el campo de la historia - del devenir histórico-. Y aquélla (Historie, se diría en alemán) supone ésta (Geschichte). Por lo tanto, la ciencia de la escritura tendría que ir a buscar su objeto en la raíz de la cientificidad. La historia de la escritura debiera volverse hacia el origen de la historicidad (Derrida 2017, pp. 37-38). 
El cuestionamiento del origen y el valor del arjé es el punto de partida de la problemática de la huella y de la escritura, afirmación que Derrida pone en relación con la finitud. En efecto, el pensamiento de la temporalidad por medio del huella es finito porque se resiste a ser reunido consigo mismo en ninguna de sus dimensiones: pasado y futuro. La finitud marca así en Derrida la imposibilidad del origen, precisamente por lo contrario de lo que ocurre en Heidegger, donde la temporalidad es finita solo en la medida en que es originaria, la finitud es, en este caso, lo originario mismo. Ahora bien, si finitud es el nombre de la imposibilidad del origen, esto señala una brecha entre el ente, el tiempo y la historia. A su vez, el pensamiento de la huella marca la imposibilidad del origen: «[...] un origen cuya estructura se deletrea así — significante de un significante — se excede y borra a sí mismo en su propia producción» (Derrida 2017, p. 12).

Para Derrida la finitud implica la imposibilidad misma del origen en el sentido obvio de que el Dasein no es el origen de su ser (Dastur 1994, p. 64). Una vez más, lo que está en cuestión es la sintaxis y no los conceptos mismos. El pasado absoluto, un pasado sin origen es la única posibilidad del futuro. La pasividad de un pasado que no es un pasado-presente es también la relación con el futuro que no es futuro-presente. Cada momento temporal depende de un soporte de inscripción espacial, en consecuencia, el soporte material y espacial de la huella es la condición para la síntesis del tiempo desde que permite que el pasado sea retenido para el futuro. En efecto, en la imposibilidad de que una historia deconstructiva pueda comenzar con el origen único de una «historicidad auténtica», se concreta la ruptura que Derrida opera con el modo de pensamiento fenomenológico. Un buen ejemplo del pensamiento de la historia desde la más radical noción de différance es el análisis del no-origen como suposición de proximidad. Ya hemos visto que en relación al ser, el $D a$ ni está cerca ni lejos, el hecho de que el $D a$ se resista a una designación simplemente espacial o antropológica, puede vincularse a una historicidad que hace posible la diferencia ontológica y la excede. De forma que la historicidad pone de manifiesto la imposibilidad de un punto de partida puro en la absoluta proximidad de lo óntico o lo ontológico. El origen no es una categoría histórica, nada puede tener lugar sobre la base de un puro comienzo. Ahora bien, este rechazo del origen no supone en absoluto el rechazo de la génesis. Marrati (2005, p. 108) describe este gesto como la condición para una «historicidad en general» que no permanece ni simplemente en la historia (como un historicismo empírico), ni fuera de la historia (como una posibilidad ahistórica, trascendental). La apertura o génesis de la historia, su condición de posibilidad, ni es dentro ni fuera de la historia, en la medida en que fuera 
de la historia seguiría funcionando como un origen ahistórico, y dentro de la historia se reduciría a un mero hecho empírico entre otros:

El litigio, la diferencia entre Dioniso y Apolo, entre el impulso y la estructura, no se borra en la historia, pues no está en la historia. Es también, en un sentido insólito, una estructura originaria: la apertura de la historia, la historicidad misma. La diferencia no pertenece simplemente ni a la historia ni a la estructura (Derrida 2012, p. 44)

El pensamiento de Derrida sobre esta contaminación irreductible de lo empírico y lo trascendental, lo finito y lo infinito, encuentra su paradigma en la escritura. No obstante, el espaciamiento entre la Historie y Geschichte necesita mantenerse, si bien, este espaciamiento no se corresponde con la distinción heideggeriana, sino que la retención del envío es pensada como origen en la medida en que nada le precede y nada ulterior le excede en la historia a la que da lugar. Ahora bien, de ser así, sugeriría que la historia que inaugura está ya, en cierto modo, programada por anticipado, esto es, el «envío del ser» (Geschick des Seins) originario nos envía la historia, pero como un destino. Es un hecho destacado que mientras la Destruktion de Heidegger intenta remontar a los orígenes de dominios enteros de actividad humana, para Derrida fuera de un texto no hay origen histórico, metafísico o trascendental, si por origen se entiende una presencia determinada, ya que una vez que hemos deconstruido la idea de tal presencia, el origen desaparece excepto en el texto. Esos orígenes son generados por el texto y afirmar su pretensión de validez extra-textual equivale a convertirlos en significados trascendentales, algo propio de la razón metafísica. Sin embargo, sería un error tanto inferir que para Derrida la idea de origen carece de interés, como sostener que Heidegger está comprometido con orígenes simples de naturaleza pre-textual. Las palabras son en sí mismas orígenes, como lo atestiguan sus prolongadas meditaciones sobre logos, moira y aletheia. Además, la misma noción de origen no es simple, por cuanto se trata más de un abismo (Abgrund) que de un fundamento. Es la insistencia de Heidegger en la reunión en el origen lo que revela los límites de su tarea destructora, manifiesta en el recurso continuo a palabras con el prefijo «ge-» para designar una reunión o agrupación, por ejemplo en: Geviert, ge-eignet, Ge-stell, Geschick. El empleo de esta última es especialmente notable porque se refiere a la forma en que el ser se origina en «épocas»: das Geschick des Seins es un envío, el destino de un origen reunido del ser.

Derrida se pregunta si el origen no estará ya dividido sin perspectiva de reunificación excepto por mor de una astucia metafísica, si no será todo comienzo en diferido, incluso si una diferencia tal en el lugar del origen no sería la condición para que haya un Geschick, un envío del ser, una dispensación del ser y el tiempo, del presente y de la representación: «[...] no 
hay ya origen simple. Puesto que lo que es reflejado se desdobla en sí mismo y no sólo porque se le adicione su imagen. El reflejo, la imagen, el doble desdobla aquello que duplica. El origen de la especulación se convierte en una diferencia» (Derrida 2017, p. 48). De modo que a la reunión inicial del envío del ser Derrida opone la posibilidad de varios envíos, lo que supone la negación de la posibilidad misma de que alguno de ellos funcione como origen. Se trata de un envío preontológico que no se junta más que dividiéndose, difiriéndose, no originario, que no comienza consigo mismo aunque nada presente le preceda, que no emite más que remitiendo, no emite sino a partir de lo otro: «Todo comienza con el remitir, es decir, no comienza» (Derrida 2017b, p. 15). Desde el momento que esa fractura divide de entrada todo remitir siempre hay una multiplicidad de remisiones, huellas que remiten a otras huellas. Esta divisibilidad o différance es la condición para que haya envío. El concepto de «anacronía» (Derrida 2012, p. 36) denota la imposibilidad del origen, desde que origen no pude ser pensado fuera de la noción de reunión. Se trata de un origen diferido que funciona como un desplazamiento trascendental al que en De la gramatología Derrida llama «huella», «archi-escritura» y «différance».

La différance no acontece en un momento concreto dentro de una historia dada, lo que no implica que deba ser entendida como una estructura sincrónica y atemporal, más bien se trata de la dimensión de la historicidad en general, algo que no debe confundirse con una eternidad ahistórica o con algún momento empíricamente determinado en el transcurso de la historia fáctica:

La huella no sólo es la desaparición del origen; quiere decir aquí —en el discurso que sostenemos y de acuerdo al recorrido que seguimos- que el origen ni siquiera ha desaparecido, que nunca fue constituida salvo, en un movimiento retroactivo, por un no-origen, la huella, que deviene así el origen del origen (Derrida 2017, p. 80).

Este origen inscrito encarna una «historicidad radical» o «archi-historia» en la medida en que no siendo nada en sí mismo, aparte de este movimiento de auto-disimulación que ya vimos también en la consideración de la historia como metáfora, prescribe la historia, debido a lo que las operaciones de términos tales como el origen inscrito, la huella, la différance, requieren una «historicidad radical» en virtud de su carácter auto-disimulador, y, por tanto, Derrida siempre los considera históricos «si hubiera alguna historia», naturalmente.

Derrida sostiene que su propio pensamiento lleva las huellas de una historicidad mayor que lo que generalmente se llama historia, razón por la que deseaba alejarse de la historia. Llegados a este punto, debemos preguntarnos con Derrida por el núcleo semántico mínimo de aquello que puede recibir el nombre de «historia», reparando en el riesgo de reapropiación metafísica en 
cuanto se plantea la pregunta por el concepto o el sentido, por la historicidad de la «historia», la esencia, la quidditas, de ahí la necesidad de cambiar el concepto tradicional y sus implicaciones:

El carácter metafísico del concepto de historia no está únicamente vinculado a la linealidad, sino a todo un sistema de implicaciones (teleología, escatología, acumulación relevante e interiorizante del sentido, un determinado tipo de tradicionalismo, un determinado concepto de continuidad, de verdad, etc.) (Derrida 2014, p. 90).

En efecto, si el concepto de historia implica preguntarse por la esencia que lo regula, por lo tanto, la pregunta por la historia de la esencia y, en última instancia, por la historia del sentido del ser, la necesidad de una estrategia de trabajo textual que cambie el concepto tradicional de historia se antoja imprescindible a fin de evitar que sea reapropiado metafísicamente, asumiendo el riesgo implícito en la conceptualización misma, de ahí que haya siempre que interrogar a los conceptos desde la especificidad de su historia y su articulación con los demás campos históricos del texto general:

[...] el concepto de historia no ha vivido más que de la posibilidad del sentido, de la presencia pasada, presente o prometida del sentido, de su verdad. Fuera de ese sistema no se puede recurrir al concepto de historia más que reinscribiéndole en otro lugar, según una estrategia específica y sistemática (Derrida 2007, p. 276).

Los conceptos no son átomos significativos ni entidades autónomas sino que se inscriben en cadenas significantes que son las que le procuran su carácter netamente metafísico. Cuando la historia se escribe se hace repetible, iterable, la repetición misma puede llegar a ser una parte de otra cadena conceptual extraída de su contexto inicial, porque siempre es posible para los conceptos escapar a sus contextos y solicitar cualquier horizonte semántico o hermenéutico: «Repetición y primera vez, pero también repetición y última vez, pues la singularidad de toda primera vez hace de ella también una última vez» (Derrida 2012, p. 24). Antes que comenzar con un momento originario construido en el presente y basado sobre la asunción material del pasado como si realmente hubiera ocurrido, Derrida establece a partir del huella, una lógica del fantasma o lo que siguiendo a Kleinberg (2017) hemos denominado, «archi-historia».

La reinscripción del concepto de historia en una nueva cadena conceptual y la emergencia del cuasi-concepto pone en crisis la historiografía o la historia fáctica, ahora convertida en el lugar de la emergencia de los fantasmas. Si bien, los historiadores, al otorgar al acontecimiento pretérito la entidad ontológica de un objeto fijo, inmutable, perfectamente localizable y determinable en sus 
cualidades, trabajan como si el «archivo» ${ }^{7}$ estuviera completo, hay aspectos del pasado que nos acechan, son los fantasmas de las cosas olvidadas o borradas del archivo, propiedades ontológicas del acontecimiento pasado que asedian el relato histórico como un fantasma que no está presente ni ausente, ni está aquí y ahora, ni ha partido para siempre según la lógica de la huella regulada por la différance, sino que después del fin, la singularidad de toda primera vez hace de ella también una última vez, la singularidad que define al «acontecimiento». A esta lógica del asedio Derrida la denomina con el neologismo «fantología» (Derrida 2012, p. 24). La lógica del fantasma se piensa desde «la no contemporaneidad consigo mismo del tiempo presente» (Ibid. 38).

Con el término francés hantologie (homónimo de ontologie), se ofrece un presente asediado por los fantasmas del pasado, la «fantología» sería entonces esta lógica del asedio más potente que un pensamiento del ser.

\section{CONCLUSIONES}

Dos son las razones, a juicio de Derrida, por las que Heidegger hacia el final de Ser y tiempo "pierde el aliento» (Derrida 2016, p. 161): (1) el arraigo de la historicidad en la temporalidad del Dasein y (2) la ausencia de nuevas categorías apropiadas para pensar lo que aún tiene que ser pensado. Dos razones que solo son una y la misma. Se parte del tiempo como horizonte trascendental del ser para hablar de la historia y sobre el ser faltan categorías, «la penuria de los medios "categoriales" disponibles y la incertidumbre de los horizontes ontológicos primarios se agudizan en la misma medida en que el problema de la historia es llevado a un enraizamiento originario» (Heidegger 2018, p. 391). Determinar el tiempo como el horizonte trascendental de la cuestión del ser, sigue siendo un gesto metafísico, por eso el «giro» (kehre) tiene lugar cuando Heidegger se plantea el tema de la historia y la cuestión del ser más allá de la analítica del Dasein. Derrida observa que cuanto más se remita el problema de la historicidad a su raíz, la temporalidad, más elusivos se vuelven sus medios categoriales y su horizonte. En adelante, el tema de la temporalidad irá desapareciendo paulatinamente como horizonte trascendental en la pregunta por el ser, en consecuencia, el tema de la historicidad es gradualmente liberado de la temporalidad.

Las características principales del replanteamiento que Derrida lleva a cabo

7 En Derrida (1997) el concepto de «archivo» se aleja de la idea de un registro o monumentalización del evento pasado, de un pasado que a su vez resulta disponible, completo, si no que se orienta hacia un «otro» al que podríamos responder por permanecer abierto a lo que comienza al regresar (volver) desde el futuro, el evento como advenir del archivo. 
de lo trascendental como «cuasi-trascendental», conduce a una reconfiguración de la historicidad como un infinito abierto, cuya indeterminación permite a su vez un replanteamiento de la Historie que ya no se opone a la Geschichte. El pensamiento de la huella marca la imposibilidad del origen, solo el pasado absoluto, un pasado que no ha sido pasado-presente, se abre a la posibilidad del futuro en virtud de que cada momento temporal depende de un soporte de inscripción espacial, de este modo, el soporte material y espacial de la huella es la condición que permite la retención del pasado para el futuro. En consecuencia, fuera del texto no hay origen histórico, si por origen se entiende una presencia determinada, de ahí que el objetivo de Derrida sea concebir una historicidad que no esté dentro ni fuera de esta historia, algo finito, textual y engastado en un movimiento interminable de metáforas, una «historicidad radical» o una «archi-historia».

Ahora estamos en condiciones de entender por qué Derrida abandona la noción de «historicidad» tras 1965, y la razón por la que en De la gramatología sostiene que el concepto mismo de «historia» se inscribe aún dentro de una época logocéntrica. Nada de lo anterior implica un rechazo el concepto de «historia», solo expresa una cautela, una precaución ante la pregunta por su esencia y por la historia de la esencia, porque la pregunta por «la historicidad de la historia» es ya en sí misma histórica en la medida en que el sentido, la esencia, el significado, la conciencia, etc., están determinados históricamente, de ahí que la filosofía de la historia no sea más que la propia historia de la filosofía.

Por otro lado, como tantas veces se ha dicho, los conceptos mismos no son metafísicos, lo es su sintaxis dentro de un cierto marco conceptual, de modo que Derrida emplea el concepto de «historia» estratégicamente a fin de producir una nueva conceptualización, a partir de un trabajo textual que se aleja del discurso dominado por la esencia, el sentido, la verdad, etc., obteniendo de resultas un cuasi-concepto que cae bajo una nueva lógica de la repetición y la huella, como parte integrante del texto general y reglado por una economía de la différance, esto es, una temporalidad no-lineal y libre del imperio del sujeto-conciencia dispensador de sentido.

\section{REFERENCIAS BIBLIOGRÁFICAS}

BENNINGTON, G. y DERRIDA, J. 1993: Jacques Derrida. Chicago: The University of Chicago Press.

DERRIDA, J. 1989: La deconstrucción en las fronteras de la filosofía. tr. Peñalver Gómez, P. Barcelona: Paidós.

DERRIDA, J. 1995: Dar (el) tiempo. tr. de Peretti, C., Barcelona: Paidós. 
DERRIDA, J. 2005: La verdad en pintura. tr. González, M.C. y Scavino, D. Buenos Aires: Paidós.

DERRIDA, J. 2007: La diseminación. tr. Arancibia, J.M. Madrid: Fundamentos.

DERRIDA, J. 2012: La escritura y la diferencia. tr. Peñalver, P. Barcelona: Anthropos.

DERRIDA, J. 2012: Espectros de Marx. tr. de Peretti, C. de, Madrid: Trotta.

DERRIDA, J. 2013: Márgenes de la filosofía. tr. González Marín, C. Madrid: Cátedra.

DERRIDA, J. 2014: Posiciones. tr. Arranz, M, Valencia: Pre-Textos.

DERRIDA, J. 2017: De la gramatología. tr. del Barco, O y Ceretti, C. Ciudad de México: Siglo XXI.

DERRIDA, J. 2016: Heidegger: The Question of Being \& History. tr. Bennington, G. Chicago: The University of Chicago Press.

DERRIDA, J. 1987: Mal de archivo. Una impresión freudiana. tr. Vidarte, P. Madrid: Trotta.

DERRIDA, J. 2017: Psyché. Invenciones del otro. tr. Cragnolini, M.B. et ál., Avellaneda: La Cebra.

DASTUR, F. 1994: La Mort. Essai sur la finitude. Paris: Hatier.

GASCHÉ, R. 1986: The Tain of the Mirror. Harvard: Harvard University Press.

GASTON, S. 2019: Jacques Derrida and the Challenge of History. New York: Rowman \& Littlefield.

HEIDEGGER, M. 2009: Tiempo e historia. tr. Escudero, J. A. Madrid: Trotta.

HEIDEGGER, M. 2010: ¿Qué significa pensar? tr. Gabás, R. Madrid: Trotta.

HEIDEGGER, M. 2015: Hitos. tr. Cortés, H. y Leyte, A. Madrid: Alianza.

HEIDEGGER, M. 2018: Ser y tiempo, tr. Jorge Eduardo Rivera C., Madrid: Trotta.

HUSSERL, E. 2013: Ideas relativas a una fenomenología pura y una filosofía fenomenológica 1. tr. Gaos, J. y Zirón Quijano, A. México: Fondo de Cultura Económica.

KATES, J. 2005: Essential History. Evanston: Northwestern University Press.

KLEINBERG, E. 2017: Haunting History, California: Stanford University Press.

MARRATI, P. 2005: Genesis and Trace. tr. Sparks, S. Stanford: Stanford University Press.

PERETTI de, C. 1989: Jacques Derrida: Texto y deconstrucción. Barcelona: Anthropos.

POTESTÀ, A. 2017: «Contar historias: Heidegger y Derrida pensadores de la historicidad».Kriterion, 137,pp.235-249.doi:10.1590/0100-512X2017n13701ap

ROCHA, D. 2018: «La historia de Heidegger y Derrida, o cómo no contar historias». Ápeiron. Estudios de filosofía - Monográfico «Artes de la controversia. Homenaje a Quintín Racionero», 8, pp. 177-187.

RONALD MENDOZA-DE, J. 2017: «Historicity as Metaphoricity in Early Derrida From the History of Being to Another Historiography. The New Centennial Review, 17.1, pp. 43-72.

RAPAPORT, H. 1989: Heidegger \& Derrida. Nebraska: University of Nebraska Press.

WOOD, D. 1989: The Deconstruction of Time. Evanston: Northwestern University Press. 
Marco Antonio Nunez Cantos es Profesor de Enseñanza Media de Filosofía y Licenciado en Filología Hispanica y Filosofía por la UNED. Actualmente participa como investigador en formación en la Escuela Internacional de Doctorado de la UNED

Lineas de investigación

Martin Heidegger, Jacques Derrida, Historicidad y huella

Publicaciones recientes

2021: «Envío, acontecimiento \& catástrofe. La correspondencia entre Heidegger y Derrida». Thémata Revista de Filosofía. no 63 • enero-junio (2021) pp. 339-358. ISSN: 0212-8365 • e-ISSN: 2253-900X • DOI: 10.12795/themata.2021.i63.17.

2016: «La palabra lacerada. Celan desde Derrida». Thémata Revista de Filosofía. N $^{\circ}$ 54, julio-diciembre (2016) pp.: 111-124. ISSN: 0212-8365 e-ISSN: 2253-900X doi: 10.12795/themata.2016.i54.06

Correo electrónico: mnunez65@alumno.uned.es 
